\title{
Grief Reactions and Coping Strategies to Parental Loss among in-School Adolescents in Kwara State, Nigeria
}

\section{Samuel Kolawole Ajiboye}

$\mathrm{PhD}$. Department of Counsellor Education, Faculty of Education, University of Ilorin, Ilorin, Nigeria, ajiboye.sk@unilorin.edu.ng

\section{Michael Ajokpaniovo}

M.Ed. Department of Counsellor Education, Faculty of Education, University of Ilorin, Ilorin, Nigeria

This study investigated grief reactions and coping strategies of in-school adolescents faced with parental loss in Ilorin, Nigeria. The study adopted the descriptive design of the survey method. Two hundred in-school adolescents were drawn using simple random sampling and purposive sampling techniques. A questionnaire tagged "Grief Reactions and Coping Strategies Questionnaire (GRCSQ) was used for the research. The instrument possessed a reliability coefficient of 0.82 which was established through the test retest method. Two research questions and two null hypotheses were generated and tested using the measure of central tendency and ttest statistical tool respectively. The result revealed that in-school adolescents faced with parental loss experienced series of grief reactions such as anxiety, nervousness, fear, nightmare and shock. These in-school adolescents faced with parental loss have low coping abilities. İt was further revealed that there is no significant difference in the grief reactions to parental loss and coping strategies among in-school adolescents based on gender. The researchers recommended that counsellors should constantly organize grief counselling for in-school adolescents who have lost their parents; grief therapy programme which could help to manage various levels of grief reaction among students should be coordinated by the counsellors and help-giving professionals.

Keywords: grief reactions, parental loss, coping strategies, in-school adolescents, bereavement

\section{INTRODUCTION}

The death of a parent is the most monumental loss that a child can experience. It is believed that children cannot understand death and lack the capacity to grieve. Because of this misconception, coupled with confusion and anxiety in communicating with children about death, children are often told that the dead parent has simply "gone away." Shielding children from death deprives them of the ability to grieve and ultimately heal (Patterson, 2009). The age and stage of development of a child at the time of his or her parent's death strongly influences the ways in which the child reacts and adapts to the loss. Patterson (2009) stated that an understanding of the child's emotional and cognitive development can enable caregivers and professionals to determine how best to communicate about death with the particular child, to understand and empathize with the child's experience and guide the child through the grieving and healing process. The early death of a parent affects a child's development, and the child's development affects how he or she will grieve and reconstruct his or her relationship with the deceased parent. Furthermore, children re-experience their grief as they reach each milestone in their development. Garber (1988), quoting the poem by Shel Silverstein stated that the deceased parent is a "missing piece" that the child needs.

Citation: Ajiboye, S. K., \& Ajokpaniovo, M. (2019). Grief Reactions and Coping Strategies to Parental Loss among inSchool Adolescents in Kwara State, Nigeria. Anatolian Journal of Education, 4(1), 85-92. https://doi.org/10.29333/aje.2019.418a 
to reconstruct in order to provide himself with a "history of his past that he could then build on, alter and modify with changing developmental concerns... During each succeeding developmental stage, he may need to step back and...reconstitute the missing piece" (Garber, 1988, p. 272).

Worden (1996), a notable grief counsellor and expert, identified four tasks of mourning: accepting the reality of the loss; experiencing the pain and emotional aspects of the loss, adjusting to an environment without the deceased; and relocating the dead person in one's life. The satisfactory completion of these tasks depends on both the child's stage of development at the time of the death and his or her adaptability and ability to attend to any unfinished tasks at later stages of development. Whether a parent dies through old age, unexpectedly, or from disease, children are left with a range of emotions ranging from emptiness and loneliness to guilt and anger. The most common grieving effects/emotions and normal reactions include: confusion, anxiety, remorse, fear, frustration, yearning, and depression (All Psychology Careers, 2014). Psychological research, such as that of Maxine (2014) has shown that an adolescent's age affects his/her ability to cope with the death of the parent. Maxine in her book "The Lifelong Impact of the Early Death of a Mother or Father," mentioned that the loss of a parent before adulthood has a profound effect on the rest of that person's life. The loss affects adult personality development, a sense of security, and relationships with the surviving parent and significant others. Loss of a parent at an early age has been shown to lead to long-term psychological damage in children, especially when the parent lost is the mother. Children almost always exhibit some type of regression behaviour when a parent dies. It is important to recognize these behaviours as part of grieving and not to punish the child for them. Children might resort to a behaviour they had left behind, such as thumb sucking, bed wetting, or uncontrolled crying. Behavioural grief symptoms in children include: withdrawal, searching for the deceased, avoiding places and people who remind them of the deceased, changes in eating habits, and crying. Physical symptoms of grief include: weakness, low energy, dry mouth, and shortness of breath.

Coping with parental death is not the same from one adolescent to another. For this reason, some teens coping strategies can include involvement in sports or becoming consumed with schoolwork. Spirituality has also been identified as a means of decreasing grief reactions from parental death (Lawrence-Webb \& Okundaye, 2006). Another common way youths and children cope with parental death is through voracious eating or inability to control eating choices when traumatic events rob bereaved youth of their ability to control their emotions and stability in life (Beam, Servaty-Seib, \& Mathews, 2004). Eating disorders are multidimensional and can begin because of many different life experiences. Recent research is beginning to highlight significant connections between traumatic childhood experiences, such as parental death and eating disorders (Beam, Servaty-Seib, \& Mathews, 2004). Therefore, it is important for family members and teachers to allow adolescents to feel independent while remaining available to provide the emotional support and guidance that they still do need.

\section{Statement of the Problem}

Grief is not a "one size fits all" proposition. Many factors affect a child's grief process and adjustment to life without the dead parent. When a child experiences the death of a parent, the emotional trauma can be devastating. But until recently, few studies have examined the impact of this type of loss relative to the age of the child and the quality of parenting that the child received after the loss. Nickerson, Bryant, Aderka, Hinton, and Hofmann (2011) sought to determine how parental death affected children across their life span. They found out that as the life span progresses and the individual reaches adulthood, the psychological and interpersonal consequences of this disturbance may manifest in long-term mental health problems. Lawrence, Jeglic, Matthews and Pepper (2006) investigated gender differences in grief reactions following the death of a parent and found no gender differences between bereaved students on measure of psychological stress. However, Bekkers (2013) 
discovered that males limited their expression of emotion because they did not want to appear weak, hence the device more coping strategies than female counterparts. Ravies, Siegel and Karus (1999), in a study entitled "Children's Psychological Distress Following the Death of a Parent," girls were found to likely experience depressive symptoms after the loss of a parent than boys. Additionally, younger children were more at risk for depressive symptoms than older children. Most of the studies on grief reactions were conducted outside the shore of Nigeria, hence the present study deemed it fit to investigate grief reactions and coping strategies for parental loss among in-school adolescents in Kwara State, Nigeria.

\section{Research Questions}

1. What are the grief reactions to parental loss among in-school adolescents in Kwara States, Nigeria?

2. What are the coping strategies adopted by in-school adolescents faced with parental loss in Kwara States, Nigeria?

3. Would there be significant difference in grief reactions to parental loss among in-school adolescents based on gender.

4. Would there be significant difference in the coping strategies adopted by in-school adolescents faced with parental loss based on gender.

\section{METHOD}

The descriptive survey type of research design was adopted for the study. Thus, questionnaire type of instrument was used to gather information from a sample of the population of the study. The questionnaire was tagged "Grief Reactions and Coping Strategies Questionnaire (GRCSQ) and has three sections; Sections A, B, C: the demographic data; grief reactions and coping strategies. The instrument was patterned in four-point Likert-type rating scale. Thus, any item on the instrument that has a mean score of 2.50 and above was considered a significant grief reaction or coping strategy because the highest and lowest mean scores are 4 and 1 respectively while the average is 2.50 $(4+3+2+1=10 / 4)$. The instrument was subjected to the test retest method in which the thirty forms of the questionnaire were administered twice to respondents who possessed similar characteristics of the intended participants at an interval of four weeks. The two sets of scores were correlate using the Pearson Product Moment Correlation (PPMC) formula, which yielded a reliability coefficient of 0.83 . A total of 200 in-school adolescents who have lost their parents within a period of five years were purposively selected to participate in the study. This was done through the students' information records in the various schools selected for the study. The researchers administered the instrument to the respondents while the results were subjected to the descriptive and inferential (percentages, measures of central tendency, t-test and Analysis of Variance) statistics. All hypotheses were tested at 0.05 alpha level of significance.

\section{FINDINGS}

\section{Demographic Data}

Table 1

Distribution of Respondents by Gender

\begin{tabular}{lcc}
\hline Gender & $f$ & $\%$ \\
\hline Male & 82 & 41.0 \\
Female & 118 & 59.0 \\
Total & 200 & 100.0 \\
\hline
\end{tabular}


The result in Table 1 shows that 59\% (118) of the respondents were female and $41 \%$ (82) of the respondents were males. This shows that more females participated than males.

Research Question 1: What are the grief reactions to parental loss among in-school adolescents?

Table 2

Mean and Rank Order of Grief Reactions to Parental Loss among In-School Adolescents

\begin{tabular}{lcc}
\hline As a victim of parental loss, I experience: & $\overline{\mathrm{X}}$ & Rank \\
\hline anxiety & 3.47 & $1^{\text {st }}$ \\
Nervousness & 3.41 & $2^{\text {nd }}$ \\
fear & 3.38 & $3^{\text {rd }}$ \\
Nightmare & 3.24 & $4^{\text {th }}$ \\
Shock & 3.15 & $5^{\text {th }}$ \\
difficulty concentrating & 3.07 & $6^{\text {th }}$ \\
Anger & 2.95 & $7^{\text {th }}$ \\
Guilt & 2.81 & $8^{\text {th }}$ \\
numbness & 2.73 & $9^{\text {th }}$ \\
irregular body temperature & 2.56 & $10^{\text {th }}$ \\
headaches & 2.49 & $11^{\text {th }}$ \\
Tiredness & 2.43 & $12^{\text {th }}$ \\
Denial & 2.32 & $13^{\text {th }}$ \\
tightness in the chest & 2.31 & $14^{\text {th }}$ \\
Stomach aches & 2.28 & $15^{\text {th }}$ \\
\hline
\end{tabular}

The result in Table 2 provides answer to Research Question 1. Ten out of the fifteen items on grief reactions of respondents have mean scores above the cut-off point of 2.50 . The grief reactions to parental loss among in-school adolescents are anxiety, nervousness, fear, nightmare, shock, difficulty concentrating, anger, guilt, numbness and irregular body temperature.

Research Question 2: What are the coping strategies adopted by in-school adolescents faced with parental loss?

Table 3

Mean and Rank Order of In-School Adolescents' Coping Strategies for Parental Loss

\begin{tabular}{lcc}
\hline I cope with grief reactions from parental loss by employing: & $\overline{\mathrm{X}}$ & Rank \\
\hline self-encouragement to speak freely about the deceased parent & 2.85 & $1^{\text {st }}$ \\
taking drugs to sleep off in order to avoid memory of the loss & 2.78 & $2^{\text {nd }}$ \\
Participating in religious activities & 2.65 & $3^{\text {rd }}$ \\
listening to inspirational music & 2.57 & $4^{\text {th }}$ \\
telling my teacher and friends about the loss & 2.53 & $5^{\text {th }}$ \\
avoiding stories about death & 2.50 & $6^{\text {th }}$ \\
having people remember my deceased parents with good memories & 2.49 & $7^{\text {th }}$ \\
not wanting to see a cemetery or a dead person around & 2.47 & $8^{\text {th }}$ \\
bringing back memories of activities shared together & 2.46 & $9^{\text {th }}$ \\
being involved in school recreational activities & 2.46 & $9^{\text {th }}$ \\
joining peer support groups & 2.44 & $11^{\text {th }}$ \\
having relations and friends visit me more often & 2.41 & $12^{\text {th }}$ \\
drinking alcoholic beverages & 2.39 & $13^{\text {th }}$ \\
keeping myself busy with movies and cartoons & 2.38 & $14^{\text {th }}$ \\
eating anything eatable & 2.35 & $15^{\text {th }}$ \\
\hline
\end{tabular}

The result in Table 3 reveals that respondents significantly adopted only few coping strategies for parental loss because only six out of the fifteen items have mean scores above the cut-off (2.50) point. The coping strategies employed by respondents are: self-encouragement to speak freely about the 
deceased parent, taking drugs to sleep off in order to avoid memory of the loss, participating in religious activities, listening to inspirational music, telling my teacher and friends about the loss and avoiding stories about death.

Research Question 3: Would there is no significant difference in the grief reactions to parental loss among in-school adolescents based on gender?

Table 4

The Mean, Standard Deviation and t-test Result Showing Grief Reactions from Parental Loss Faced by In-School Adolescents Based on Gender

\begin{tabular}{lclllcll}
\hline Gender & $\mathrm{n}$ & $\overline{\mathrm{x}}$ & $\mathrm{s}$ & $\mathrm{df}$ & Cal. t-val & Crit. t-val & $p$ \\
\hline Male & 82 & 45.57 & 6.53 & 198 & 0.76 & 1.96 & 0.11 \\
Female & 118 & 44.84 & 6.74 & & & & \\
\hline
\end{tabular}

The $p$-value (0.11) is greater than the alpha level (0.05) hence the null hypothesis was accepted which suggests that male and female respondents were similar in their grief reactions to parental loss.

Research Question 4: Would there be significant difference in the coping strategies adopted by inschool adolescents faced with parental loss based on gender?

Table 5

The Mean, Standard Deviation and t-test Result Showing Coping Strategies Adopted by In-School Adolescents Faced with Parental Loss Based on Gender

\begin{tabular}{lclllclc}
\hline Gender & $\mathrm{n}$ & $\overline{\mathrm{x}}$ & $\mathrm{s}$ & $\mathrm{df}$ & Cal. t-val & Crit. t-val & $p$ \\
\hline Male & 82 & 43.74 & 6.38 & 198 & 1.35 & 1.96 & 0.07 \\
Female & 118 & 42.55 & 5.89 & & & & \\
\hline
\end{tabular}

The result in Table 5 reveals the $p$-value $(0.07)$ is greater than alpha level $(0.05)$ the null hypothesis was accepted, which depicts similarity in coping strategies for parental loss between male and female respondents.

\section{CONCLUSION}

It could be concluded that grief reaction to parental loss among in-school adolescents are numerous but the most significant are feelings of anxiety, nervousness, fear, nightmare, shock, difficulty concentrating, anger, and guilt. The respondents adopted low coping strategies, which could account for the high grief reactions exhibited. Some of the significant coping strategies employed by respondents are: self-encouragement to speak freely about the deceased, joining peer support groups, reading scriptural passages about the section of the dead, and avoiding stories about death. Since the respondents adopted few coping strategies, that may explain why they experienced many grief reactions. Both male and female respondents were similar in their grief reaction and coping strategies

\section{DISCUSSION}

The result in Table 2 provided answer to Research Question 1 which sought to establish the grief reaction to parental loss among in-school adolescents. Since the respondents alluded to most of the items in the instrument, it depicted that grief reactions to parental loss among in-school adolescents are therefore high. Nevertheless, among the most significant grief reactions are anxiety, nervousness, fear, nightmare, shock, and anger. The result supports the earlier finding of Leighton (2008) which reported that bereaved adolescents experienced significant biological, cognitive, emotional and social breakdown such as fear, nervousness, body pains, difficulty in assimilating school works and isolation. Furthermore, Lawrence, Jeglic, Matthews and Pepper (2006) found that is global phenomenon among young people regardless of socio-demographic factors. The reason for these grief reactions could be 
linked to the fact that adolescents have an understanding of death as a permanent separation with the attendant consequences on the children of the deceased. In addition, the feeling of separation caused by the loss of the parent could exert trauma on the in-school adolescents whose primary concern of educational attainment might have been affected, hence manifestation of grieving becomes imminent. Although the respondents expressed low coping strategies but among the significant are selfencouragement to speak freely about the deceased parent, taking drugs to sleep off in order to avoid memory of the loss and Participating in religious activities.

The result revealed that respondents adopted few coping strategies for parental loss; only six out of the fifteen items were significant strategies employed by the respondents to cope with parental loss. The coping strategies employed by respondents are: self-encouragement to speak freely about the deceased parent, taking drugs to sleep off in order to avoid memory of the loss, participating in religious activities, listening to inspirational music, telling their teachers and friends about the loss and avoiding stories about death. This agrees with the findings of Ajiboye (2012) where internally displaced inschool adolescents in Jos, Nigeria did not express much coping skills in the face of challenges encountered. Further, Lawrence, Jeglic, Matthews and Pepper (2006) reported that students with history of parental loss adopted avoidance style which was found to be inappropriate. Bekkers (2013) also found that children could not adopt adequate adjustment strategies in response to loss of parents because of many reasons which include age, level of cognitive development and social immaturity. Similarly in the present study, the reason for the inability of the respondents to develop corresponding coping strategies for parental loss could be as a result of the stage of their mental, emotional and social development which is still low to withstand much pressure or tasks like the adults. This could be aggravated by the rude shock often associated with loss of parent. One may therefore deduce that inschool adolescents generally lack the coping strategies required to adjust to the vacuum of loss of parent

There was no significant difference between male and female respondents in their grief reaction to parental loss. In an earlier study, Hope and Hodge (2006) found that high school children (both male and female) who experienced the death of a parent manifested a range of emotional and behavioural symptoms, especially in situations of traumatic loss. This implies that gender does not count in grief reactions to parental loss of in-school adolescents since loss of parent has universal effect irrespective of personal variables, especially gender.

There was no significant difference between male and female in-school adolescents in their coping strategies for parental loss. This supports the assertion of Walker and Shatter (2007) that, teens who loose loved ones experienced intense and frightening emotions that put them at risk of destructive behaviours such as drug and alcohol use, self-mutilation and other maladaptive tendencies but thus applied similar coping skills irrespective of their gender. One may adduce a reason that since the effects of parental loss bound on the children, regardless of gender, it is most likely that in-school adolescents who are bereaved would adopt similar coping strategies as may be applicable within their environment.

\section{Counselling Implication}

Based on the findings of the study one may deduce that counselling interventions, such as Bereavement Support Service, could be lacking in schools thereby exposing students with grief to great challenges. Counsellors are in the position to ensure such service is introduced and adequately implemented in order to save students experiencing grief of parental loss to adjust better. If this is not promptly and adequately provided, adolescents who grieve as a result of parental loss may resort to self-destructive behaviors. Bereavement Support Groups (BSG) can be school-based or agency-based; the counsellor has the mandate to decide and design the programme as may be suitable. It is important that counsellors' groups both male and female victims of grief together to receive the same relief 
intervention because gender is not a significant factor on grief reaction. Grief therapy, which could be coordinated by professional counsellors may involve social workers, psychologist and medical personnel in order to provide a robust service to in-school adolescents. There is thus the need to focus on improving the coping strategies among in-school adolescents who could exhibit grief reactions to parental loss. Counselling psychology has significant role to play in helping to manage grief reactions among adolescents especially within secondary school grade through organized rehabilitation.

\section{SUGGESTIONS}

Many people might not realize how traumatic and devastating death of parent can be to in-school adolescents and thereby not paying adequate attention to grief reactions among them. Based on the findings of this study, the following suggestions were made:

1. School counsellors should constantly organize grief counselling for in-school adolescents who have lost their parents. It will help to identify their grief reactions in time and savage the effects on their school activities;

2. Counsellors should coordinate different response strategies, such as Bereavement Support Group (BSG), that could instantly give attention to grief reactions among students with loss of parent.

3. Counselling Associations, in collaboration with school authorities and social workers should develop grief therapy programme which could help to manage various levels of grief reactions among students and improve their coping strategies.

4. The school's authorities, together with the efforts of the Counsellors, should liaise with families of bereaved in-school adolescents in order to collaboratively provide emotional support in the period of grieving.

\section{REFERENCES}

Ajiboye, S. K. (2012). Problems and coping strategies of internally displaced adolescents in Jos metropolis, Nigeria. Unpublished Ph.D. Seminar Paper, University of Ilorin, Ilorin.

All Psychology Careers (2014). Loss of a parent. Retrieved February 20, 2014 from http://www.allpsychologycareers.com/topics/loss-of-a-parent.html

Beam, M. R., Servaty-Seib, H. L., \& Mathews, L. (2004). Parental loss and eating-related cognitions and behaviors in college-age women. Journal of Loss and Trauma, 9(3), 247-255.

Bekkers, T. (2013). Gender difference in grief. Retrieved December 16, 2017 from

Garber, B. (1988). Construction and Reconstruction in a Case of Parent Loss. In Altschul, S. (Ed.) Childhood Bereavement and its Aftermath. Madison, Ct.: International Universities Press.

Hope, R. M., \& Hodge, D. M. (2006). Factors affecting Children's adjustment to the death of a parent: The social work Professional's viewpoint. Child \& Adolescent Social Work Journal, 25(1), 107-126.

Lawrence, E., Jeglic, E. L., Matthews, L. T., \& Ppper, C. M. (2006). Gender difference in grief reactions following the death of a parent. OMEGA Journal of Death and Dying, 52 (4): 323-337.

Lawrence-Webb, C. \& Okundaye, J. N. (2006). African American intergender relationship: A theoretical exploration of roles, patriarchy, and love. Journal of Black Studies, 34 (5): 623-639

Leighton, S. (2008). Bereavement therapy with adolescents: Facilitating a process of spiritual growth. Journal of Child \& Adolescent Psychiatric Nursing, 21(1), 24-34. 
Maxine, H. (2014). The loss that is forever: The lifelong impact of the early death of a mother or father $\left(4^{\text {th }} \mathrm{Ed}\right)$. Washington, Plume Books.

Nickerson, A., Bryan, R., Aderka, I. M., \& Hofmann, S. (2011). The impacts of parental loss and adverse parenting on mental health: Findings from the National Comorbidity Survey- Replication. Psychological Trauma Theory Research Practice and Policy, 5 (2): 119-127.

Patterson, T. R. (2009). Evaluating professional development. Thousand Oaks, CA: Corwin Press.

Ravies, V. H., Siegel, K. \& Karus, D. (1999). Children's psychological distress following the death of a parent. Journal of Youth and Adolescence, 28 (2): 165-180

Walker, P., \& Shaffer, M. (2007). Reducing depression among adolescents dealing with grief and loss: A program evaluation report. Health \& Social Work, 32(1), 67-68.

Worden, W. J. (1996). Children and grief: When a parent dies. New York: The Guilford Press. 